DE

M E D I C I N A

T R O P I C A L

$\mathrm{DE}$

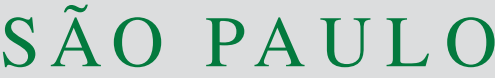

JOURNAL OF THE SÃO PAULO INSTITUTE OF TROPICAL MEDICINE

${ }^{1}$ Alabama State University, Center for Nanobiotechnology Research, Montgomery, Alabama, USA

${ }^{2}$ USDA, ARS, NEA, BARC, ABBL, Beltsville, Maryland, USA

${ }^{3}$ Auburn University, Harrison School of Pharmacy, AU Research Instrumentation Facility, Auburn, Alabama, USA

${ }^{4}$ Nanosurf, Inc., Woburn, Massachusetts, USA

Correspondence to: Shreekumar Pillai Alabama State University, Center for Nanobiotechnology Research, 1627 Harris Way, 36101-0271, Montgomery, Alabama, USA

Tel: +1 334 229-7501

E-mail: spillai@alasu.edu

Received: 30 October 2017

Accepted: 15 February 2018

\section{Evaluation of $E$. coli inhibition by plain and polymer-coated silver nanoparticles}

\author{
D'Andrea Ashmore ${ }^{1}$, Atul Chaudhari' ${ }^{2}$, Brandi Barlow' ${ }^{1}$, Brett Barlow', \\ Talia Harper ${ }^{1}$, Komal Vig ${ }^{1}$, Michael Miller ${ }^{3}$, Shree Singh ${ }^{1}$, Edward Nelson ${ }^{4}$, \\ Shreekumar Pillai ${ }^{1}$
}

\section{ABSTRACT}

Escherichia coli causes various ailments such as septicemia, enteritis, foodborne illnesses, and urinary tract infections which are of concern in the public health field due to antibiotic resistance. Silver nanoparticles (AgNP) are known for their biocompatibility and antibacterial activity, and may prove to be an alternative method of treatment, especially as wound dressings. In this study, we compared the antibacterial efficacy of two polymer-coated silver nanoparticles either containing 10\% Ag (Ag 10\% + Polymer), or 99\% Ag (AgPVP) in relation to plain uncoated silver nanoparticles (AgNP). Atomic force microscopy was used to characterize the nanoparticles, and their antibacterial efficacy was compared by the minimum inhibitory concentration (MIC) and bacterial growth curve assays, followed by molecular studies using scanning electron microscopy (SEM) and (qRT- PCR). AgNP inhibited the growth of $E$. coli only at $0.621 \mathrm{mg} / \mathrm{mL}$, which was double the concentration required for both coated nanoparticles $(0.312 \mathrm{mg} / \mathrm{mL})$. Similarly, bacterial growth was impeded as early as $8 \mathrm{~h}$ at $0.156 \mathrm{mg} / \mathrm{mL}$ of both coated nanoparticles as compared to 0.312 $\mathrm{mg} / \mathrm{mL}$ for plain AgNP. SEM data showed that nanoparticles damaged the cell membrane, resulting in bacterial cell lysis, expulsion of cellular contents, and complete disintegration of some cells. The expression of genes associated with the TCA cycle (aceF and $f r d B$ ) and amino acid metabolism ( $\mathrm{gadB}, \mathrm{met} L, \arg C$ ) were substantially downregulated in $E$. coli treated with nanoparticles. The reduction in the silver ion $\left(\mathrm{Ag}^{+}\right)$concentration of polymer-coated AgNP did not affect their antibacterial efficacy against $E$. coli.

KEYWORDS: Escherichia coli. Polymer coated. Nanosilver

\section{INTRODUCTION}

Microorganisms possess several mechanisms of resistance that interfere with the effectiveness of antibiotics. Indiscriminate use of antibiotics for the treatment of bacterial infections has caused resistant strains of broad spectrum gram negative (-) bacteria such as $E$. coli which are difficult to treat ${ }^{1}$ Nanoparticles have been under scrutiny due to their anti-inflammatory, antibacterial, and antimicrobial properties. Nanoparticles range in size from 1-100 nm and function at a molecular and cellular level. Electronic and structural properties of nanoparticles significantly differ from the respective bulk particles ${ }^{2,3}$. There are important components in the utilization of nanoparticles that include cellular uptake, adsorption, and metal ion release. Once the nanoparticles are released into the cell, the nanoparticles are engulfed through a process called endocytosis. The release can sometimes cause a severe cellular side effect called oxidative stress ${ }^{4}$. 
Silver nanoparticles (AgNP) have been of interest because the agent possesses many of the properties that are common to nanoparticles ${ }^{1,4,5}$. Silver nanoparticles have shown to be promising in wound healing, implantations, wound disinfection, sensing, catalysis, the coating of other surfaces, etc. ${ }^{6-10}$. The small size of AgNP is representative of a massive surface area, which increases the interaction of nanoparticles and the microorganism ${ }^{1,4}$. The nanoparticles are able to enter the cell membrane in an easier way due to a greater surface area with respect to volume ratio of smaller nanoparticles. The mechanism by which silver nanoparticles act is not fully understood. Some studies indicate that the AgNP may cause antibacterial cell death due to silver ions that prevent DNA replication or inactivating cellular proteins. There are also interactions with the cell membrane in which the structure is damaged resulting in cell death ${ }^{3,11}$. Other theories suggest that silver nanoparticles cause cell death through cell lysis and thiol reactions that inactivate enzymes $^{3,12}$. Another possible mechanism may be due to oxidative stress, inflammation, and DNA damage ${ }^{13}$. Toxicity has been a subject of concern in regard to application of silver nanoparticles within the human body ${ }^{7,14}$. The smaller nanoparticles have the strongest antimicrobial activity; however, they are the most cytotoxic ones. Silver nanoparticles are typically coupled with other agents to improve efficacy and reduce cytotoxicity ${ }^{1}$.

Silver nanoparticles have been modified by coating with polymers such as polyvinylpyrrolidone (PVP), polyethylene glycol (PEG), polyvinyl alcohol (PVA), citrate and sodium dodecyl sulfate (SDS) acting as capping and stabilizing agents to improve antibacterial activity ${ }^{11,15-20}$. The coating of a particular surface and its effects are based on the size and surface area ${ }^{12}$. The protective coating created by polymers such as PVP, PEG, PVA, citrate, and SDS promotes the interaction of the AgNP with the bacterial cells ${ }^{12}$. Although polymer coating does not directly increase bactericidal activity, it stabilizes the silver particles so that they do not autoaggregate to a larger biomass which hinders biological activity ${ }^{21}$. There are several studies that show the antibacterial effectiveness of AgNP with capping agents where the MIC was lower. For example, a study was conducted that showed AgNP stabilized with PVP and PVA showed lower MIC values than the original $\mathrm{AgNP}^{22}$. In yet another study, the effectiveness of PVP capped AgNP was more obvious than citrate or SDS capped $\mathrm{AgNP}^{19,23}$. Many studies have shown the antibacterial effectiveness of AgNP capped with several stabilizing agents and a silver ion $\left(\mathrm{Ag}^{+}\right)$ concentration of $99.99 \%$. However, there are currently no studies that investigate the antibacterial activity of AgNP with a silver ion $\left(\mathrm{Ag}^{+}\right)$concentration of $10 \%$ and coated with a polymer.
In the current study, we used three different nanoparticles that included Ag 99\% +PVP (AgPVP), Ag 10\% + Polymer, and plain uncoated AgNP in order to determine the antibacterial effectiveness of reduced silver ion $\left(\mathrm{Ag}^{+}\right)$ concentrations in coated silver nanoparticles relative to plain AgNP against E. coli. We characterized the 3 nanoparticles by Atomic Force microscopy. Then, we assessed the antibacterial activity of all $3 \mathrm{AgNPs}$ by using the MIC and growth curve assays. In addition, in order to understand the probable mechanisms of action of AgPVP, $\mathrm{Ag} \mathrm{10 \%} \mathrm{+} \mathrm{Polymer,} \mathrm{and} \mathrm{AgNP,} \mathrm{we} \mathrm{performed} \mathrm{electron}$ microscopy and molecular studies using quantitative reverse transcriptase polymerase chain reaction (qRT-PCR).

\section{MATERIAL AND METHODS}

\section{Description and sources of AgPVP, Ag 10\% + Polymer, and AgNP}

Ag 10\% + Polymer were purchased from Nanostructured \& Amorphous Materials, Inc. (Houston, TX 77084, USA). The Ag $10 \%$ + Polymer contained (90\% w) Nanopowder, 25 Particle size: $<=15 \mathrm{~nm}$, Composition: $10 \%$ Silver $+90 \%$ synthetic Polymer, Stock \#7023Hz, Lot \#7023-123109. AgPVP and AgNP were purchased from US Research Nanomaterials, Inc. (Houston, TX, USA). The AgPVP contained $99.99 \% \mathrm{Ag},(20 \mathrm{~nm}$ w/ 0.2 PVP, Stock \#US1037, CAS \#7440-22-4=. The AgNP contained Ag 99.99\%, (20 nm, metal basis), Stock \#US 1038, CAS \#7440-22-4

\section{Atomic force microscopy}

Nanoparticle colloidal solutions were deposited on freshly cleaved mica and left to air dry. AFM measurements were performed in air using a Nanosurf Flex-Axiom (Nanosurf AG, Liestal, Switzerland) in dynamic mode using a commercially available ACST-A cantilever (AppNano, Mountain View, CA). After acquisition, all AFM images were line-flattened. Nanoparticle sizes were measured using the software provided by the manufacturer.

\section{Bactericidal experiments}

Escherichia coli clinical isolate Serotype 6 (ATCC $^{\circledR}$ 25922) was purchased from American Type Culture Collection (ATCC, VA USA) and used for the bacterial experiments. The bacteria were grown at $37{ }^{\circ} \mathrm{C}$ in LuriaBertoni (LB) broth (Difco, Sparks, MD, USA) overnight in an orbital shaker and the optical density (OD) was measured at $600 \mathrm{~nm}$. The antibacterial activity of AgPVP, Ag 10\% + Polymer, and AgNP were determined using the minimum 
inhibitory concentration (MIC) assay. An in-depth evaluation of the antibacterial activity of Escherichia coli was done utilizing the growth curve assay. Morphological changes in Escherichia coli treated with AgPVP, Ag 10\% + Polymer, and AgNP were assessed by scanning electron microscopy (SEM). The evaluation of genes expression was performed using the quantitative real time reverse transcriptase polymerase chain reaction (qRT-PCR).

\section{Determination of MIC}

The MIC values of AgPVP, Ag 10\% + Polymer, and AgNP were examined in quadruple wells of 96-well microtiter plates using the broth microdilution assay ${ }^{24}$. Escherichia coli cultures were serially diluted to a $\log$ phase of $1 \times 10^{6} \mathrm{CFU} / \mathrm{mL}$ and then exposed to two-fold decreasing concentrations of AgPVP, Ag 10\% + Polymer, and AgNP starting at $1.25 \mathrm{mg} / \mathrm{mL}$ until $0.039 \mathrm{mg} / \mathrm{mL}$. The serial dilutions were made in LB broth used as a diluent. All the plates consisted of 6 dilutions of the AgPVP, Ag 10\% + Polymer, and AgNP dispersion solutions, 1 negative control, (no AgPVP, Ag 10\% + Polymer, AgNP or bacterial culture), and 1 positive control (bacterial culture without AgPVP, Ag 10\% + Polymer, and AgNP). The 96-well plates were sealed with a parafilm cover that offered some ventilation and incubated at $37^{\circ} \mathrm{C}$ for $24 \mathrm{~h}$.

The MIC was determined after incubation by the turbidity of the culture media in the wells. The concentration of the first well without turbidity was considered as the minimum inhibitory concentration. The inhibition of bacterial growth was measured by reading the Optical Density (OD) of the cultures at an absorbance at $600 \mathrm{~nm}$ with a TECAN Sunrise ${ }^{\mathrm{TM}}$ enzyme-linked immunoabsorbent assay (ELISA) plate reader (Tecan US, Inc. Morrisville, NC, USA). All of the experiments were repeated at least three times.

\section{Quantitative growth analysis of Escherichia coli}

Escherichia coli were quantified in sequence at times point $0,4,8,16$, and $24 \mathrm{~h}$ after exposure to AgPVP, $\mathrm{Ag} 10 \%$ + Polymer, and AgNP. Twenty milliliters of bacterial culture containing $1 \times 10^{5} \mathrm{CFU} / \mathrm{mL}$ were exposed to $1.25,0.621$, 0.312, or $0.156 \mathrm{mg} / \mathrm{mL}$ of AgPVP, Ag $10 \%$ + Polymer, and AgNP which were based on the MIC values of AgPVP, Ag $10 \%$ + Polymer, and AgNP. The bacterial cultures were incubated at $37^{\circ} \mathrm{C}$ with shaking at $300 \mathrm{rpm}$ and the optical densities at $600 \mathrm{~nm}$ (OD 600) were obtained at 0, 4, 8, 16, and $24 \mathrm{~h}$. Growth curves were generated by plotting OD vs. time points in increasing time increments using a graphing software (Sigma Plot, Systat Software, San Jose, CA).

\section{Electron microscopy}

Scanning electron microscopy (SEM, Zeiss EVO 50, Carl Zeiss Meditech, Oberkochen, Germany) was used to observe the changes of Escherichia coli treated with AgPVP, Ag 10\% + Polymer, and AgNP. Non-treated cells were used as a control. Bacterial cells $\left(1 \times 10^{5} \mathrm{CFU} / \mathrm{mL}\right)$ were treated with $0.312 \mathrm{mg} / \mathrm{mL}$ of $\mathrm{AgNP}$ or $0.156 \mathrm{mg} / \mathrm{mL}$ of AgPVP or Ag 10\% + Polymer separately for $16 \mathrm{~h}$ in an orbital shaker $(180 \mathrm{rpm})$ at $37{ }^{\circ} \mathrm{C}$. After treatment, the bacterial cells were harvested by centrifugation (14,000 x g for $15 \mathrm{~min}$.), washed in PBS, fixed in a mixture of $2.5 \%$ glutaraldehyde plus $1 \%$ formaldehyde for $24 \mathrm{~h}$, followed by further fixation in $1 \%$ aqueous osmium tetroxide for $1 \mathrm{~h}$. The pellets were then subjected to dehydration in various grades of ethanol $(30,50,70$, $80,90,95$ and 100\%). After treatment with 100\% ethanol, $5 \mu \mathrm{L}$ of each sample were placed on an SEM stub, air dried, and sputter coated with a gold-palladium alloy for SEM analysis (Zeiss EVO 50, Carl Zeiss Meditec, Oberkochen, Germany).

\section{Molecular studies using qRT-PCR}

The mRNA expression levels of $E$. coli genes associated with the citric acid (TCA) Cycle, amino acid metabolism, virulence, DNA repair and transcription were evaluated using qRT-PCR ${ }^{25,26}$. The primers used to amplify each gene and their origins are indicated in Table $1^{27-40}$. Escherichia coli $\left(1 \times 10^{5} \mathrm{CFU} / \mathrm{mL}\right)$ were treated with AgPVP, AgNP, and Ag 10\% + Polymer and incubated in an orbital shaker at $37{ }^{\circ} \mathrm{C}$, followed by complete RNA extraction using Ambion $®$ RNA extraction kits (Thermo Fischer Scientific Inc., USA). The RNA was quantified by the Nanovue Plus spectrophotometer (GE Healthcare Life Sciences, Pittsburg, PA) at $260 \mathrm{~nm} / 280 \mathrm{~nm}$ and cDNA synthesis was performed in a $40 \mu \mathrm{L}$ reaction volume using the Applied Biosystems High Capacity cDNA Reverse transcriptase Kit (Life Technologies, Grand Island, NY). The expression of various genes such as those associated with the TCA Cycle (acef, $f r d B)$, amino acid metabolism $(\arg C$, metL, $\operatorname{gadB})$, virulence $(f i c, m s b B)$, and DNA repair and transcription ( $m f D$ ) were quantified by qRT-PCR using the $\mathrm{SYBR}^{\circledR}$ Select Mastermix (Life Technologies, Grand Island, NY) according to the manufacturer's instructions. DNA samples were quantified and amplified in the Applied Biosystems ${ }^{\circledR}$ ViiA $^{\text {TM }} 7$ real-time PCR system (Life Technologies). The PCR process consisted of an initial denaturation step at $95^{\circ} \mathrm{C}$ for $2 \mathrm{~min}$, followed by 40 cycles of $95^{\circ} \mathrm{C}$ for $5 \mathrm{~s}$, $56^{\circ} \mathrm{C}$ for $25 \mathrm{~s}$ and $72^{\circ} \mathrm{C}$ for $30 \mathrm{~s}$. The amplification efficacy of each primer set in relation to the endogenous control 
Table 1 - Primers used

\begin{tabular}{|c|c|c|c|}
\hline Gene & Forward 5'-3' & Reverse 5'-3' & Function \\
\hline aceF & CAGATGCCTCGCTTCAATAGT & CAGCTCGATGATGCCTTTCT & TCA Cycle $27-30$ \\
\hline $\operatorname{frdB}$ & CACGGTAAGAAGGAGCGTATG & TCTACTTTGCCCTGCTGAATG & TCA Cycle ${ }^{31-33}$ \\
\hline metL & CGACAGCGGCGATACTATTT & GATCCACCAGCTCGGTAAAC & Amino Acid Metabolism 30 \\
\hline $\operatorname{gadB}$ & CACGGTAAGAAGGAGCGTATG & TCTACTTTGCCCTGCTGAATG & Amino Acid Metabolism ${ }^{30,34}$ \\
\hline $\arg C$ & CCTGGCAACCAGACATAAGA & CATATGCGGATGGCGATTTAC & Amino Acid Metabolism ${ }^{30,35}$ \\
\hline flic & ACAGCCTCTCGCTGATCACTCAA & GCGCTGTTAATACGCAAGCCAGAA & Virulence ${ }^{30,36,37}$ \\
\hline$m s b B$ & ATCGCTTTAACGCCGCCAAAGTTC & TACGTTCTGGAAAGCAGAGCGACA & Virulence $^{30,38}$ \\
\hline$m f D$ & TCAGGAAGCTGGAAGGTAATG & GGACCATCAAGGCGGTAAT & DNA Repair and Transcription $30,39,40$ \\
\hline
\end{tabular}

gene (16sRNA) was between 95-98\% (data not shown). Data generated from three independent experiments were used to determine the relative gene expression compared to non-treated samples by the $2-\Delta \Delta \mathrm{Ct}$ method $^{25,26}$.

\section{Statistical analyses}

Analyzed data were expressed as the mean \pm standard deviation (SD) performed using the GraphPad Prism Version 4 software (GraphPad Software, Inc., La Jolla, CA). The statistical differences for the growth curve assays were determined by using two-way ANOVA. The fold change expression of genes was analyzed by the Student's t-test. The differences were considered to be statistically significant when the $\mathrm{P}$-values were $\leq 0.05$ or highly significant at $\mathrm{P} \leq 0.01$.

\section{RESULTS}

\section{Atomic Force Microscopy}

AFM analysis of AgPVP, Ag 10\% + Polymer, and $\mathrm{AgNP}$ is shown in Figure 1. The average radius of the Ag $10 \%$ + polymer particles ranged from 23 to $27 \mathrm{~nm}$, whereas for the AgPVP, it ranged from 30 to $33 \mathrm{~nm}$ and, for the AgNP, it ranged from 30 to $42 \mathrm{~nm}$. Overall, it appeared that the polymer-coated nanoparticles (Figure 1B and C) were more spherical and uniformly dispersed, whereas the AgNP were irregular in shape and varied more in their size (Figure 1A). The polymer coating was more apparent on the Ag10\% + polymer samples (Figure 1C).

Antibacterial activity of AgPVP, Ag 10\% + Polymer and AgNP

We tested the antibacterial activity of AgPVP, Ag 10\%+ Polymer, and AgNP. The MIC values for AgPVP, Ag 10\% + Polymer, and AgNP were between $0.312 \mathrm{mg} / \mathrm{mL}$ and 0.625
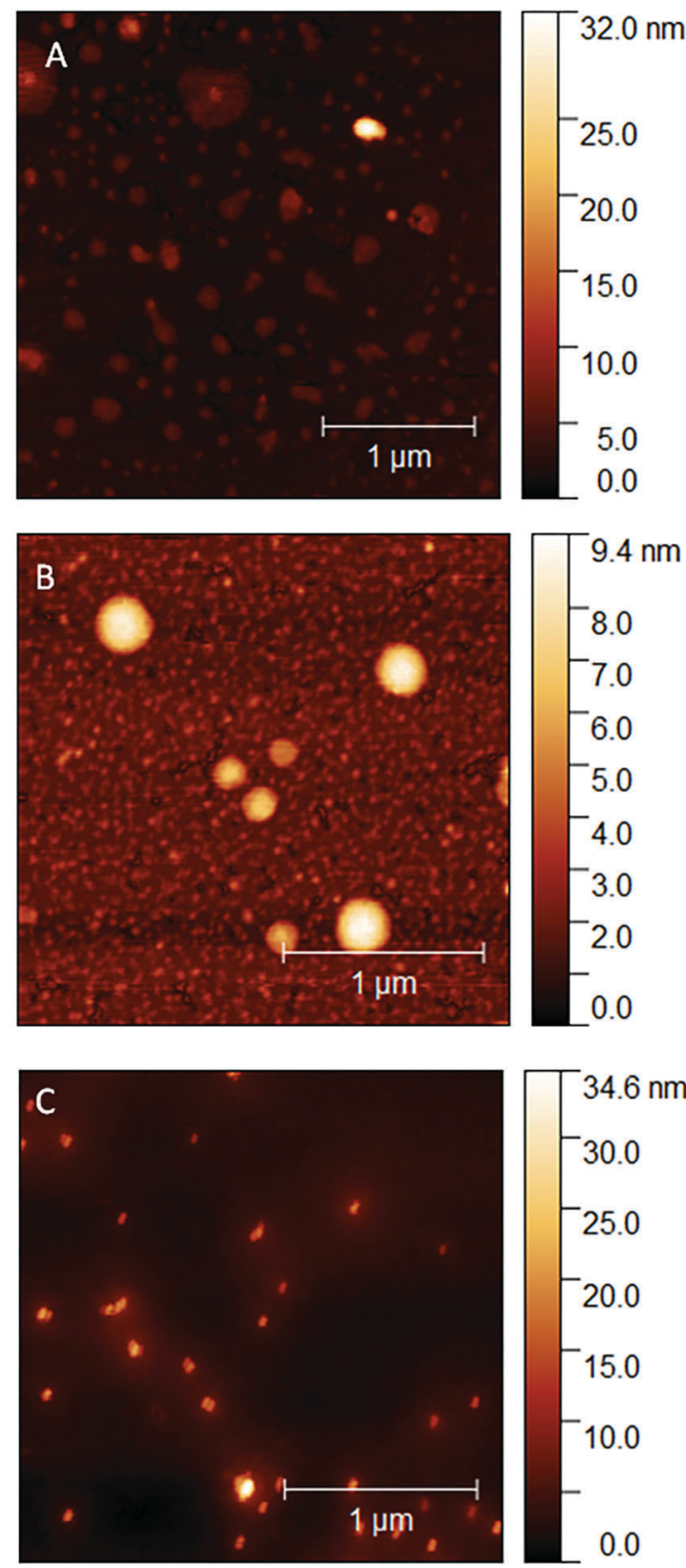

Figure 1 - Atomic force spectroscopy analysis Ag NP (A), AgPVP (B), Ag 10\% + polymer (C) 
$\mathrm{mg} / \mathrm{mL}$ for $E$. coli (Table 2). The growth curve assay of $E$. coli exposed to varying concentrations of AgNP exhibited inhibition in a time and concentration dependent manner. The concentration in which the inhibition was noticeable was at $0.312 \mathrm{mg} / \mathrm{mL}$ (Figure 2A). In contrast, E. coli bacterial cells treated with Ag 10\% + Polymer and AgPVP demonstrated significant inhibition at a lower concentration of $.156 \mathrm{mg} / \mathrm{mL}$ (Figure 2B and 2C). The comparison is exhibited by the reduction of bacterial numbers and growth as time progressed.

\section{EM analysis of Escherichia coli exposed to AgPVP, Ag 10\% + Polymer and AgNP}

The SEM images of healthy and treated bacterial cells are shown in Figures 3, 4 and 5. The SEM evaluation indicated that treatment with AgPVP induced a morphological change of E. coli (Figure 3C and D). EM data revealed that there was a disruption of the outer cell membrane by AgNP, and cell lysis of $E$. coli seen with bacterial cells treated with AgPVP (Figure $3 \mathrm{C}$ and D), AgNP (Figure 4C and D) and Ag 10\% + Polymer (Figure 5C and D). The bacterial cells treated with $\mathrm{Ag}$ $10 \%+$ Polymer showed dramatic cell lysis with extensive cellular debris (Figure 5C and D).

Molecular studies of Escherichia coli exposed to AgPVP, Ag 10\% + Polymer and AgNP

Gene expression associated with amino acid metabolism, TCA Cycle, virulence, DNA replication and repair were investigated to explore the antibacterial activity of AgPVP, Ag 10\% + Polymer, and AgNP. Bacterial cells treated with AgNP showed a significant downregulation of the genes associated with the TCA cycle $(a c e F, \operatorname{gadB})$ and amino acid metabolism ( $m e t L, f r d B$, and $\arg C$ ) (Figure 6). There was also substantial upregulation of a gene associated with virulence ( $f l i C$ and $m \mathrm{sb} B$ ). AgPVP treated bacteria cells similarly showed significant downregulation of genes related to the TCA cycle ( $a c e F$ and $\operatorname{gadB}$ ) and amino acid metabolism (metL, $\operatorname{rrdB}$ and $\arg C$ ) (Figure 5). AgPVP treated bacteria had substantial upregulation of the virulence gene $(m s b B)$, as well as a gene associated with DNA repair and transcription ( $m f D$ ) (Figure 6). Similar changes were seen in cells treated with Ag 10\% + Polymer with downregulation of the TCA cycle (aceF and $\operatorname{gadB})$ and amino acid metabolism $(m e t L, \operatorname{frd} B$, and $\arg C)$ (Figure 6). However, the upregulation of virulence ( $m s b B$ ) and DNA repair and transcription $(m f D)$ was considerable in comparison to bacterial cells treated with AgNP and AgPVP (Figure 6).

\section{A E. coli and AgNP}

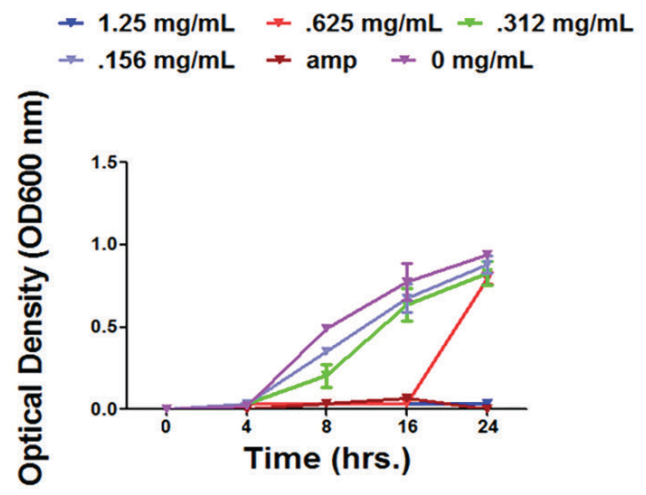

B E. coli and AgPVP

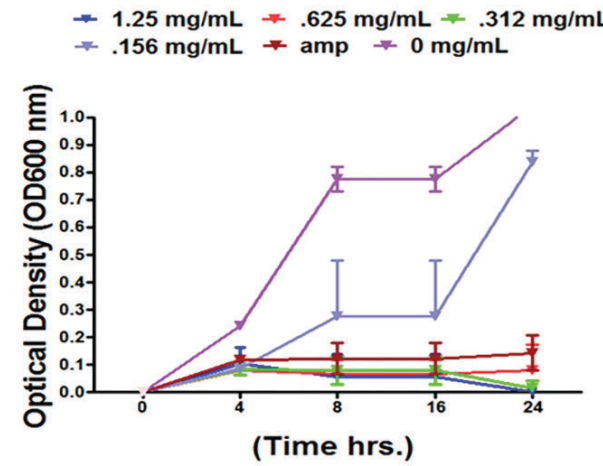

C E. coli Ag $10 \%+$ Polymer

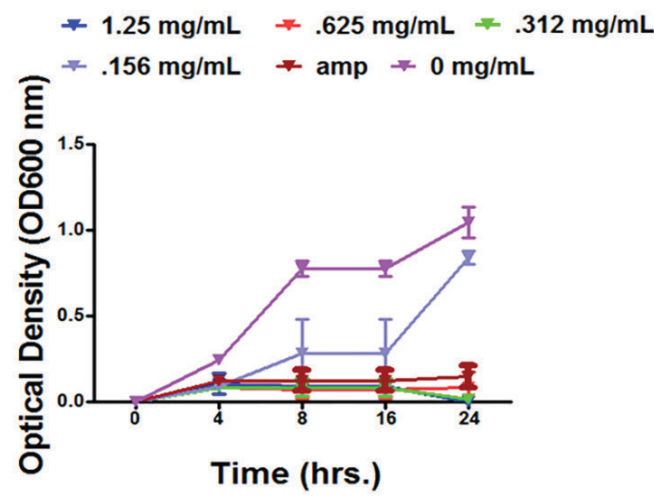

Figure 2 - Bacterial growth curve assay and quantitative analysis of $E$. coli exposed to various concentrations of AgNP, AgPVP, Ag $10 \%+$ Polymer. A) Bacterial growth curve of E. coli exposed to AgNP using optical density measurements; B) Bacterial growth curve exposed to AgPVP using optical density measurements; C) Bacterial growth curve exposed to Ag 10\% + Polymer using optical density measurements. Bacteria were grown in LB broth containing various concentrations of AgNP, AgPVP, and Ag 10\% + Polymer and all the cultures were incubated at $37^{\circ} \mathrm{C}$ with shaking at $180 \mathrm{rpm}$ and the optical density measurements at $600 \mathrm{~nm}$ (OD600) and CFU/mL counts were done at 0, 4, 8, 16, $24 \mathrm{~h}$. The results are means of three experiments with $p \leq 0.05$ indicating significant differences, or $p=0.01$ indicating highly significant differences. Error bars represent standard deviations determined from at least 3 duplicates 
Table 2 - Minimum inhibitory concentration (MIC)

\begin{tabular}{lccc}
\hline Bacterium & Nanoparticle & $\mathrm{MIC}(\mathrm{mg} / \mathrm{mL})$ & $\mathrm{MBC}(\mathrm{mg} / \mathrm{mL})$ \\
\hline \multirow{3}{*}{ E. coli } & AgNP & $0.62-0.31$ & 0.62 \\
& AgPVP & $0.31-0.15$ & 0.31 \\
& Ag $10 \%$ +polymer & $0.31-0.15$ & 0.31 \\
\hline
\end{tabular}
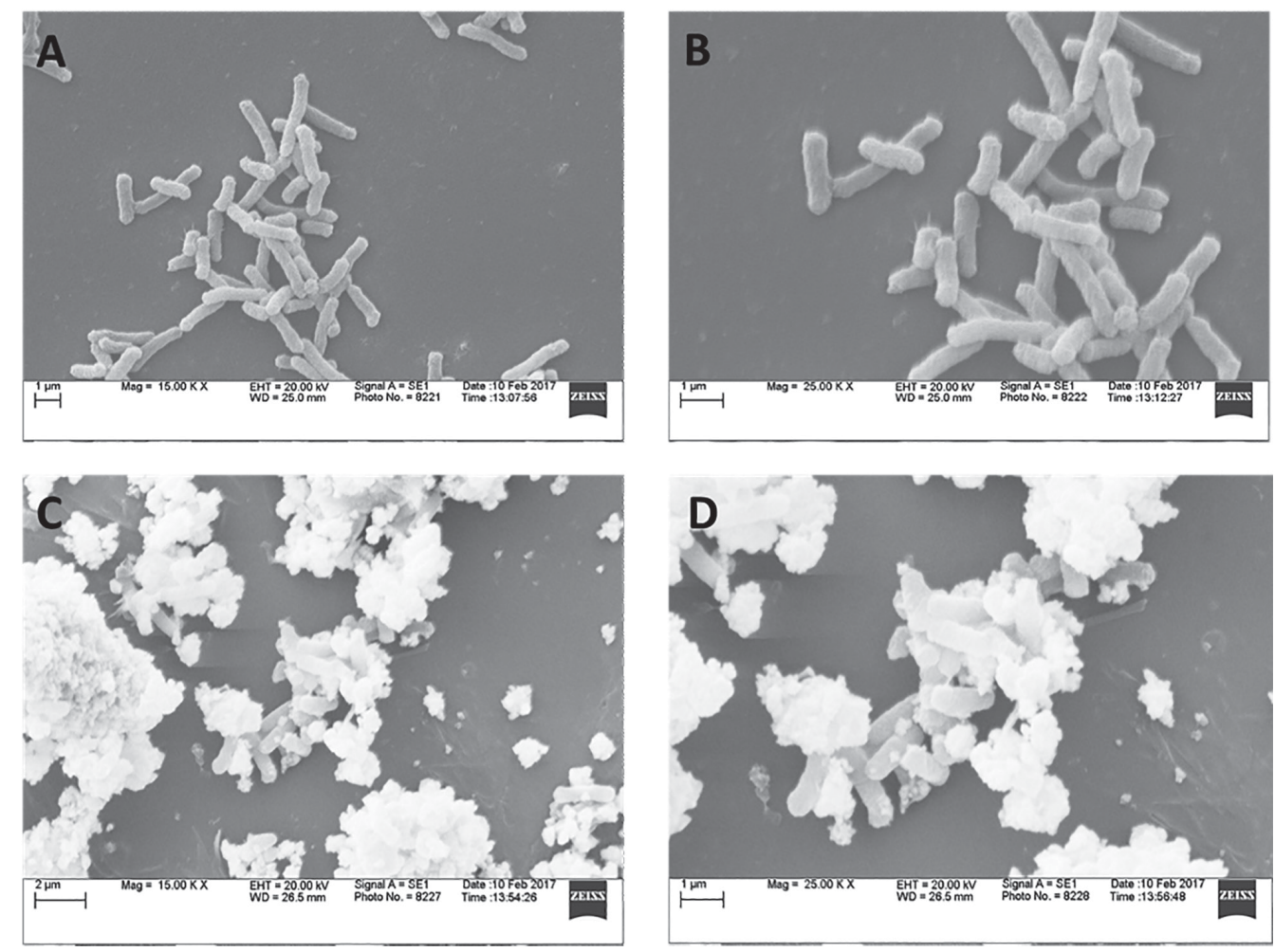

Figure 3 - Evaluation of morphological changes in bacteria upon their interaction with AgPVP. A) Untreated bacterial cells at $15 \mathrm{~K}$ magnification; B) Untreated bacterial cells at $25 \mathrm{~K}$ magnification; C) Bacterial cells treated with AgPVP at $15 \mathrm{~K}$ magnification; D) Bacterial cells treated with AgPVP at $25 \mathrm{~K}$ magnification.

\section{DISCUSSION}

The usage of AgNP has gained popularity, however, the known cytotoxicity to human cells has warranted some hesitation in the use of AgNP as an alternative therapy ${ }^{1,2,26,41,42}$. However, some studies have shown that several strains of E. coli isolated from environmental samples such as horse dung, were highly susceptible to $\mathrm{AgNP}^{43}$.

The results of our study showed that the polymer coating of AgNP does not reduce their antibacterial activity against E. coli. More importantly, the reduction in the concentration of silver ions $\left(\mathrm{Ag}^{+}\right)$in the polymer functionalized $(\mathrm{Ag}$ $10 \%+$ polymer) did not reduce the antibacterial efficacy. The findings reported here are in alignment with previous studies regarding the antibacterial activity of functionalized and coated AgNP which indicated an enhanced level of antibacterial activity and reduction in cytotoxicity ${ }^{13,44-48}$.
There have been very few findings that are contrary to our research regarding the lack of antibacterial activity of capped or functionalized AgNPs. Jain et al. ${ }^{48}$ have shown that the removal of protein capping from AgNPs improved their antibacterial activity. Membrane damage and ROS generation studies implicated that protein-capped and bare silver nanoparticles exhibit a distinct mode of action. Apparently, protein shells prevented silver ions from generating ROS since the protein shell did not allow the $\mathrm{AgNP}$ to interact directly with the membranes ${ }^{48}$. However, the present study results indicated that uncapped and bare nanoparticles were less effective as compared to polymercoated silver nanoparticles. Our study validated that AgPVP and Ag 10\% + Polymer were just as destructive against $E$. coli as AgNP, but with a two-fold reduction in the MIC value. Thus, the Ag 10\% + Polymer had only $10 \%$ of the concentration of the silver, but it was twice as effective as the AgNP and similar in efficacy to the AgPVP. This 

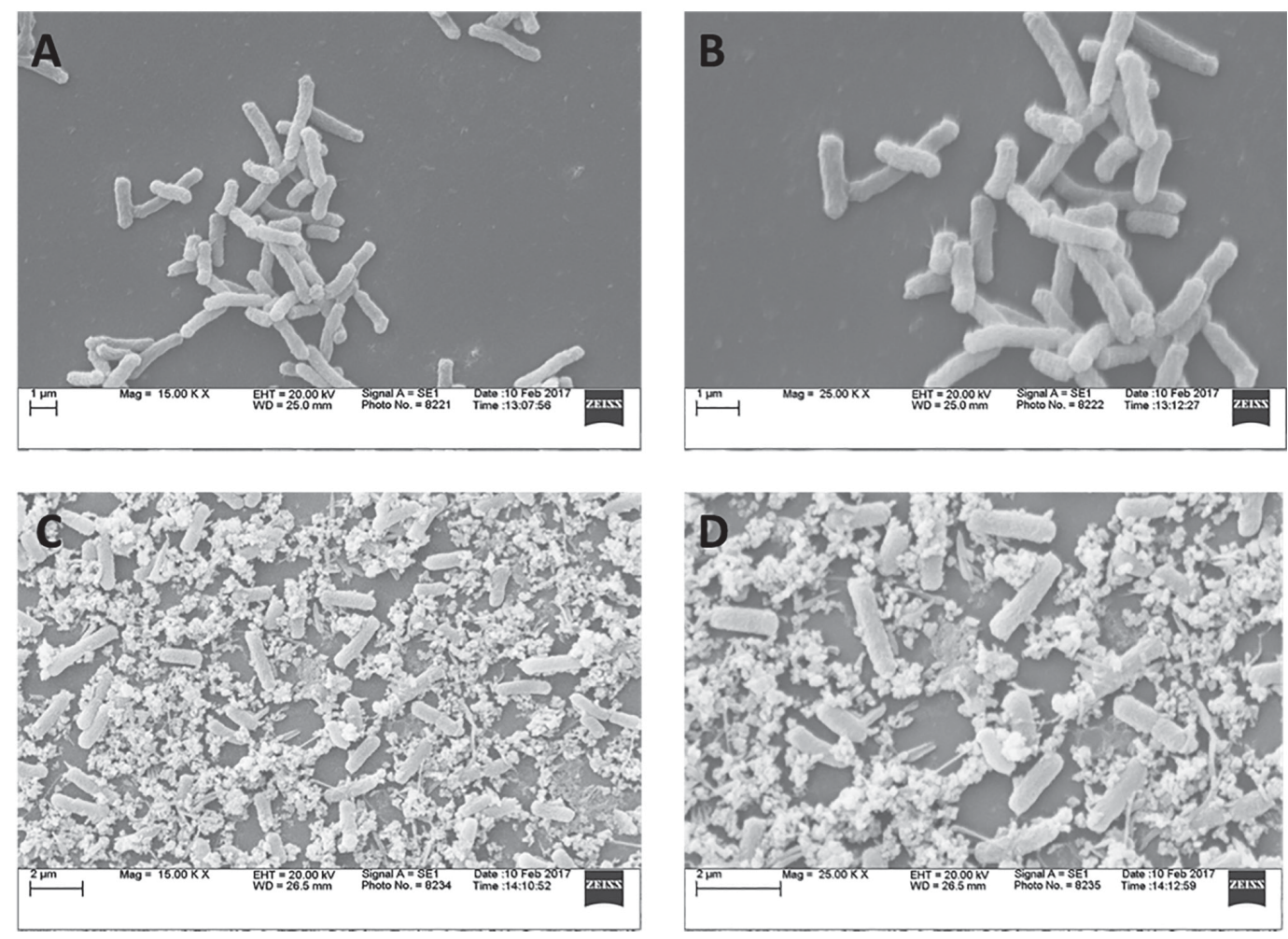

Figure 4 - Evaluation of morphological changes in bacteria upon their interaction with AgNP. A) Untreated bacterial cells at $15 \mathrm{~K}$ magnification; B) Untreated bacterial cells at $25 \mathrm{~K}$ magnification; C) Bacterial cells treated with AgNP at $15 \mathrm{~K}$ magnification; D) Bacterial cells treated with AgNP at $25 \mathrm{~K}$ magnification.
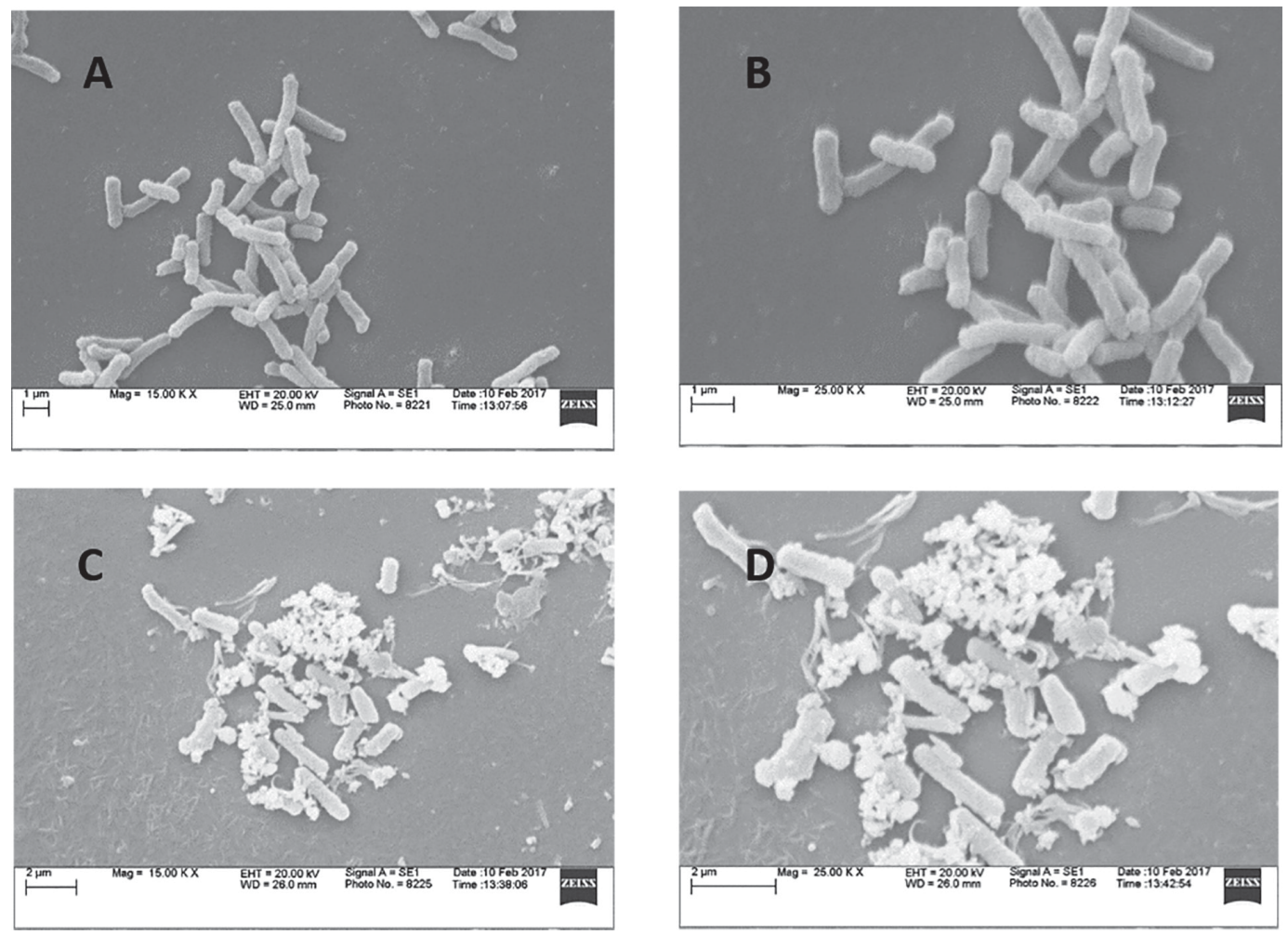

Figure 5 - Evaluation of morphological changes in bacteria upon their interaction with $\mathrm{Ag} 10 \%+$ Polymer. A) Untreated bacterial cells at $15 \mathrm{~K}$ magnification; B) Untreated bacterial cells at $25 \mathrm{~K}$ magnification; C) Bacterial cells treated with Ag $10 \%+$ Polymer at $15 \mathrm{~K}$ magnification; D) Bacterial cells treated with $\mathrm{Ag} 10 \%$ + Polymer at $25 \mathrm{~K}$ magnification. 
A

E. coli AgNP

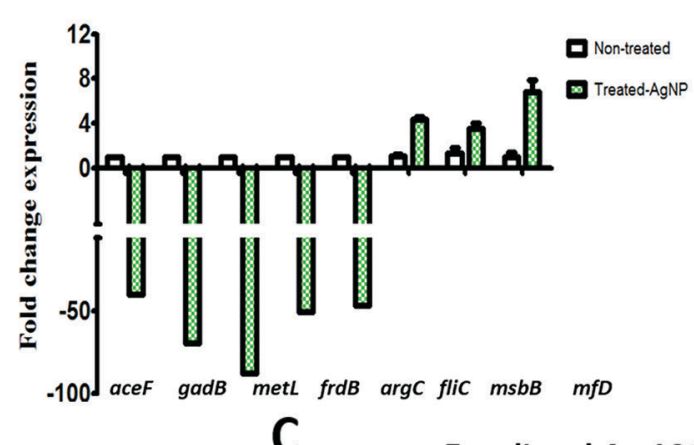

E. coli and Ag $10 \%+$ Polymer
B

E. coli AgPVP

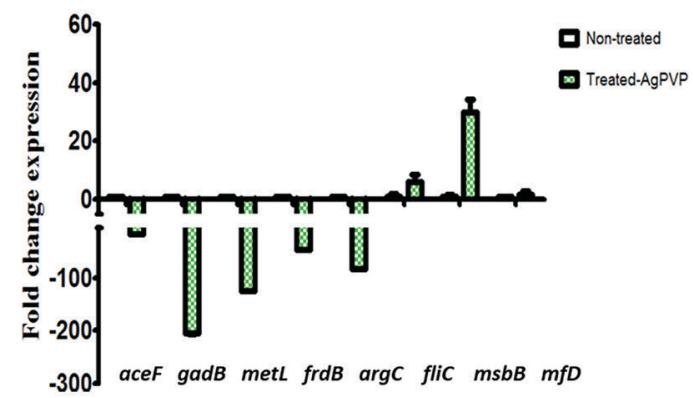

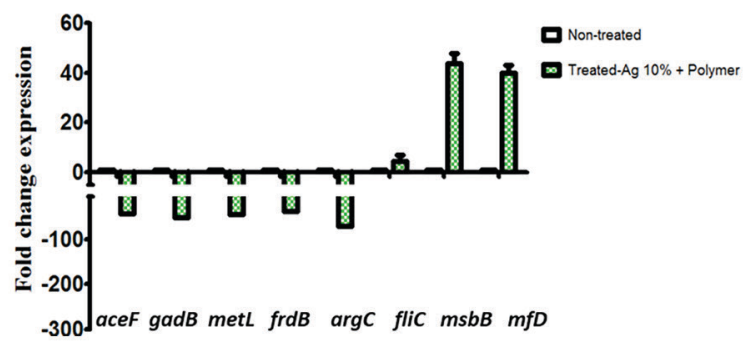

Figure 6 - Gene expression studies in E. coli exposed to AgNP, AgPVP, Ag 10\% + Polymer. A) represents gene expression of aceF, gadB, metL, frdB, $\arg C$, fliC, $m s b B$, and $m f D$ upon exposure to AgNP; B) represents gene expression of ace $F, g a d B, m e t L, f r d B, \arg C$, flic, $m s b B$, and $m f D$ upon exposure to AgPVP, and Ag $10 \%$ + Polymer; C) represents gene expression of ace $F$, gadB, metL, frdB, $\arg C, f l i C, m s b B$, and $m f D$ upon exposure to $\mathrm{Ag} 10 \%$ + Polymer. All values were expressed as fold change expressions compared to non-treated bacteria. Error bars represent standard deviations of the results determined with at least 3 biological replicates.

could result in potentially beneficial silver formulations with enhanced antibacterial activity but lower silver ion concentrations.

Nanoparticles may have different levels of activity based on structural or chemical factors ${ }^{45,47}$. Studies have suggested that the agglomeration of AgNP may turn them into less toxic substances due to the smaller surface area to volume ratio in contact with the nanoparticles ${ }^{48-51}$. The aggregation of the AgNP also lessens the antibacterial activity, however, capping or polymer functionalization enhances antibacterial activity ${ }^{45,48}$. The size and shape of nanoparticles can also play a significant role in their antibacterial activity. Smaller nanoparticles have the capacity to pass through the cell membrane while larger nanoparticles do not ${ }^{1,2,50,52}$. Typically, the most effective nanoparticles are those that have a size equal or less than $30 \mathrm{~nm}^{52,53}$. In our study, the Ag 10\% + polymer-coated NP had dimensions less than $30 \mathrm{~nm}$, whereas the AgPVP and plain uncoated AgNP were more than $30 \mathrm{~nm}$ in size. Additionally, the plain AgNP was irregular in shape, and not uniformly distributed with a mixture of small and large particles greater than $40 \mathrm{~nm}$. By comparison, AgPVP and Ag 10\% + polymer NP were circular in morphology and uniformly dispersed. This could explain why these NP were more effective than the plain uncoated AgNP. Interestingly, a previous study has shown that AgNP coated with PVP are more stable when the PVP concentration is at least $1 \%$ or higher ${ }^{54}$.

In this study, we focused on the antibacterial activity of polymer-coated and plain Ag nanoparticles. The plain silver nanoparticles had 99\% Ag, and PVP coated nanoparticles had $99 \%$ Ag plus $1 \%$ polymer, whereas the $\mathrm{Ag} 10 \%+$ polymer had only $10 \%$ of silver and $90 \%$ of polymer. Although polymer coating does not directly affect bactericidal activity, the effect of various concentrations of polymer coating could influence the outcome. Here we evaluated commercially available coated nanoparticles with the view to choose the one with the best antibacterial activity at the lowest concentration of silver. The effect of varying the polymer concentration remains to be determined. However, the present study provides insightful evidence that coating of the AgNP did not affect their antibacterial activity. Moreover, the results of the present study may suggest that the coating of AgNP indeed offers stabilization of the AgNP and thus may have a beneficiary effect on improving the antibacterial activity of AgNP.

The structural changes of $E$. coli were explored after exposure to AgPVP, Ag 10\% + Polymer, and AgNP using electron microscopy. The SEM images showed that E. coli exposed to AgPVP and Ag 10\% + Polymer had more bacteria with damaged cell membranes and lysis. 
E. coli treated with AgNP on the other hand displayed an irregularly shaped appearance with nanoparticles attached to the cell membrane and fewer damaged or lysed cells. This suggests that AgPVP and polymer functionalized NP may be more effective in penetrating the cell through damaged membranes disrupting several functions such as DNA replication, cell metabolism, cell division, etc. and cause expulsion of cellular content ${ }^{55,56}$. Silver ions have also been implicated in the inhibition of uptake of phosphorous, causing the release of mannitol, phosphate, and amino acids such as proline and glutamine outside the cell membrane through the production of reactive oxygen species (ROS) $)^{53,55,56}$.

We investigated the expression of many genes of E. coli. associated with the TCA cycle (aceF, $\operatorname{gadB})$, amino acid metabolism $(\arg C$, met $L$, and $g a d B)$, virulence $(f i C, m s b B)$, and DNA repair and transcription $(m f D)$ (Table 1). The genes associated with the TCA cycle (aceF) and amino acid metabolism $(\mathrm{gadB})$ were significantly downregulated with the treatment of AgPVP, $\mathrm{Ag} \mathrm{10 \%} \mathrm{+} \mathrm{Polymer,} \mathrm{and} \mathrm{AgNP.}$ However, there was the upregulation of genes responsible for virulence and DNA replication and repair. There was significant upregulation in flic with a 3 -fold difference in bacterial cells treated with AgNP, but flic upregulation was not significantly higher with bacterial cells treated with AgPVP and Ag 10\% + Polymer.

The upregulation of the genes required for virulence ( $m s b B$ and $f l i c$ ) and DNA replication and transcription $(m f d D$ ) may be due to a stress related response of the bacteria to the damaging effect of the various nanoparticles. It appears that the Ag 10\% + polymer NP had the highest upregulation of some of these genes suggesting that they caused more stress and damage to the bacteria than AgNP or AgPVP.

\section{CONCLUSION}

Our results indicate that capping of AgNP with PVP or functionalization with a polymer did not interfere with their antibacterial activity. The MIC and bacterial growth assay substantiated evidence that the concentration of the AgNP required to inhibit $E$. coli was reduced with polymer-coated AgNP when treating $E$. coli. The physical changes seen by SEM analysis of $E$. coli treated with various AgNP suggest that the proposed mechanisms of action include silver ions $\left(\mathrm{Ag}^{+}\right)$causing cell membrane damage or possible disruption. Finally, the molecular studies provided evidence that $E$. coli bacterial cells treated with AgNP, AgPVP and Ag 10\% + Polymer had reduced expression of various metabolism associated genes, whereas there was upregulation of some virulence and DNA repair associated genes. The upregulation was more significant in bacterial cells exposed to $\mathrm{Ag} 10 \%$ + polymer. Further research on the toxicity and molecular mechanism of action will be needed to determine the in vivo antibacterial efficacy of polymer-coated $\mathrm{AgNP}$ with a lower silver ion $\left(\mathrm{Ag}^{+}\right)$concentration.

\section{ACKNOWLEDGMENTS}

This research was supported by grants from the National Science Foundation-CREST (HRD-1241701), NSF-HBCUUP (HRD-1135863) and National Institutes of HealthMBRS-RISE (1R25GM106995-01). The department of Biological Sciences at ASU is acknowledged for providing the physical laboratory space to conduct the experiments.

\section{REFERENCES}

1. Monzillo V, Dalla Valle C, Corbella M, Percivalle E, Sassera D, Scevola D, et al. Antibacterial activity and cytotoxic effect of SIAB-GV3. New Microbiol. 2014;37:535-41.

2. Kurek A, Grudniak AM, Kraczkiewicz-Dowjat A, Wolska KI. New antibacterial therapeutics and strategies. Pol J Microbiol. 2011;60:3-12.

3. Horie M, Kato H, Endoh S, Fujita K, Komaba LK, Nishio K, et al. Cellular effects of industrial metal nanoparticles and hydrophilic carbon black dispersion. J Toxicol Sci. 2014; 39:897-907.

4. Singh K, Panghal M, Kadyan S, Chaudhary U, Yadav JP. Green silver nanoparticles of Phyllanthus amarus: as an antibacterial agent against multi drug resistant clinical isolates of Pseudomonas aeruginosa. J Nanobiotechnol. 2014;12:40.

5. Fan W, Wu D, Tay FR, Ma T, Wu Y, Fan B. Effects of adsorbed and templated nanosilver in mesoporous calcium-silicate nanoparticles on inhibition of bacteria colonization of dentin. Int J Nanomed. 2014;9:5217-30.

6. Söderstjerna E, Bauer P, Cedervall T, Abdshill H, Johansson F, Johansson UE. Silver and gold nanoparticles exposure to in vitro cultured retina - studies on nanoparticle internalization, apoptosis, oxidative stress, glial- and microglial activity. PLoS One. 2014;9:e105359.

7. Han JW, Gurunathan S, Jeong JK, Choi YJ, Kwon DN, Park JK, et al. Oxidative stress mediated cytotoxicity of biologically synthesized silver nanoparticles in human lung epithelial adenocarcinoma cell line. Nanoscale Res Lett. 2014;9:459.

8. Prestes MA, Ribas CA, Ribas Filho JM, Moreira LB, Boldt AB, Brustolin EV, et al. Wound healing using ionic silver dressing and nanocrystalline silver dressing in rats. Acta Cir Bras. 2012;27:761-7.

9. Kose N, Otuzbir A, Pekşen C, Kiremitçi A, Doğan A. A silver ionoped calcium phosphate-based ceramic nanopowder-coated prosthesis increased infection resistance. Clin Orthop Relat Res. 2013;471:2532-9. 
10. Swathy JR, Sankar MU, Chaudhary A, Aigal S, Anshup, Pradeep T. Antimicrobial silver: an unprecedented anion effect. Sci Rep. 2014;4:7161.

11. Bryaskova R, Pencheva D, Nikolov S, Kantardjiev T. Synthesis and comparative study on the antimicrobial activity of hybrid materials based on silver nanoparticles (AgNps) stabilized by polyvinylpyrrolidone (PVP). J Chem Biol. 2011;4:185-91.

12. Nymark P, Catalán J, Suhonen S, Järventaus H, Birkedal R, Clausen $\mathrm{PA}$, et al. Genotoxicity of polyvinylpyrrolidone-coated silver nanoparticles in BEAS 2B cells. Toxicology. 2013;313:38-48.

13. Franci G, Falanga A, Galdiero S, Palomba L, Rai M, Morelli G, et al. Silver nanoparticles as potential antibacterial agents. Molecules. 2015;20:8856-74.

14. Castiglioni S, Caspani C, Cazzaniga A, Maier JA. Short- and longterm effects of silver nanoparticles on human microvascular endothelial cells. World J Biol Chem. 2014;5:457-64.

15. Hamilton RF, Buckingham S, Holian A. The effect of size on Ag nanosphere toxicity in macrophage cell models and lung epithelial cell lines is dependent on particle dissolution. Int $\mathrm{J}$ Mol Sci. 2014;15:6815-30.

16. Gliga AR, Skoglund S, Wallinder IO, Fadeel B, Karlsson HL. Size-dependent cytotoxicity of silver nanoparticles in human lung cells: the role of cellular uptake, agglomeration and $\mathrm{Ag}$ release. Part Fibre Toxicol. 2014;11:11.

17. Ivask A, Kurvet I, Kasemets K, Blinova I, Aruoja V, Suppi S, et al. Size-dependent toxicity of silver nanoparticles to bacteria, yeast, algae, crustaceans and mammalian cells in vitro. PLoS One. 2014;9:e102108.

18. Van Phu D, Quoc le A, Duy NN, Lan NT, Du BD, Luan le Q, et al. Study on antibacterial activity of silver nanoparticles synthesized by gamma irradiation method using different stabilizers. Nanoscale Res Lett. 2014;9:162.

19. Kora AJ, Rastogi L. Enhancement of antibacterial activity of capped silver nanoparticles in combination with antibiotics, on model gram-negative and gram-positive bacteria. Bioinorg Chem Appl. 2013; 2013:871097.

20. Gnanadhas DP, Ben Thomas M, Thomas R, Raichur AM, Chakravortty D. Interaction of silver nanoparticles with serum proteins affects their antimicrobial activity in vivo. Antimicrob Agents Chemother. 2013;57:4945-55.

21. Lin S, Cheng Y, Liu J, Wiesner MR. Polymeric coatings on silver nanoparticles hinder autoaggregation but enhance attachment to uncoated surfaces. Langmuir. 2012;28:4178-86

22. Santos CA, Jozala AF, Pessoa Jr A, Seckler MM. Antimicrobial effectiveness of silver nanoparticles co-stabilized by the bioactive copolymer pluronic F68. J Nanobiotechnol. 2012;10:43.

23. Chen N, Song ZM, Tang H, Xi WS, Cao A, Liu Y, et al. Toxicological effects of Caco-2 cells following short-term and long-term exposure to Ag nanoparticles. Int J Mol Sci. 2016;17:974
24. Soehnlen MK, Kunze ME, Karunathilake KE, Henwood BM, Kariyawasam S, Wolfgang DR, et al. In vitro antimicrobial inhibition of Mycoplasma bovis isolates submitted to the Pennsylvania Animal Diagnostic Laboratory using flow cytometry and a broth microdilution method. J Vet Diagn Invest. 2011;23:547-51.

25. Schmittgen TD, Livak KJ. Analyzing real-time PCR data by the comparative C(T) method. Nat Protoc. 2008;3:1101-8.

26. Chaudhari AA, Ashmore D, Nath SD, Kate K, Dennis V, Singh $\mathrm{SR}$, et al. A novel covalent approach to bio-conjugate silver coated single walled carbon nanotubes with antimicrobial peptide. J. Nanobiotechnol. 2016;14:58

27. Rodriguez A, Martinez JA, Flores N, Escalante, A, Gosset G, Bolivar F. Engineering Escherichia coli to overproduce aromatic amino acids and derived compounds. Microb Cell Fact. 2014;13:126.

28. Schutte KM, Fisher DJ, Burdick MD, Mehrad B, Mathers AJ, Mann BJ, et al. Escherichia coli Pyruvate Dehydrogenase Complex is an important component of CXCL10-mediated antimicrobial activity. Infect Immun. 2015;84:320-8.

29. Cronan JE. Biotin and lipoic acid: synthesis, attachment and regulation. EcoSal Plus. 2008;3.

30. Berlyn MK. Linkage map of Escherichia coli K-12, edition 10: the traditional map. Microbiol Mol Biol Rev.1998;62:814-984.

31. Fung DK, Lau WY, Chan WT, Yan A. Copper efflux is induced during anaerobic amino acid limitation in Escherichia coli to protect iron-sulfur cluster enzymes and biogenesis. J Bacteriol. 2013;195:4556-68

32. Cole ST, Grundström T, Jaurin B, Robinson JJ, Weiner JH. Location and nucleotide sequence of $\mathrm{frdB}$, the gene coding or the iron-sulphur protein subunit of the fumarate reductase of Escherichia coli. Eur J Biochem. 1982;126:211-6.

33. Cheng VW, Tran QM, Boroumand N, Rothery RA, Maklashina $\mathrm{E}, \mathrm{Cecchini} \mathrm{G}$, et al. A conserved lysine residue controls ironsulfur cluster redox chemistry in Escherichia coli fumarate reductase. Biochim Biophys Acta. 2013;1827:1141-7.

34. Vejborg RM, de Evgrafov MR, Phan MD, Totsika M, Schembri MA, Hancock V. Identification of genes important for growth of asymptomatic bacteriuria Escherichia coli in urine. Infect Immun. 2012;80:3179-88.

35. Tchaptchet S, Fan TJ, Goeser L, Schoenborn A, Gulati AS, Sartor $\mathrm{RB}$, et al. Inflammation-induced acid tolerance genes gadAB in luminal commensal Escherichia coli attenuate experimental colitis. Infect Immun. 2013;81:3662-71.

36. Beutin L, Delannoy S, Fach P. Genetic diversity of the fliC genes encoding the flagellar antigen H19 of Escherichia coli and application to the specific identification of enterohemorrhagic E. coli O121:H19. Appl Environ Microbiol. 2015;81:4224-30

37. He Y, Xu T, Fossheim LE, Zhang XH. FliC, a flagellin protein, is essential for the growth and virulence of fish pathogen Edwardsiella tarda. PLoS One. 2012;7:e45070. 
38. Somerville JE Jr, Cassiano L, Darveau RP. Escherichia coli msbB gene as a virulence factor and a therapeutic target. Infect Immun. 1999;67:6583-90.

39. Adebali O, Chiou YY, Hu J, Sancar A, Selby CP. Genome-wide transcription-coupled repair in Escherichia coli is mediated by the Mfd translocase. Proc Natl Acad Sci. 2017;114:E2116-25.

40. Schalow BJ, Courcelle CT, Courcelle J. Mfd is required for rapid recovery of transcription following $\mathrm{UV}$-induced DNA damage but not oxidative DNA damage in Escherichia coli. J Bacteriol. 2012;194:2637-45

41. Guzman M, Dille J, Godet S. Synthesis and antibacterial activity of silver nanoparticles against gram-positive and gram-negative bacteria. Nanomedicine. 2012;8:37-45.

42. El-Zahry MR, Mahmoud A, Refaat IH, Mohamed HA, Bohlmann H, Lendl B. Antibacterial effect of various shapes of silver nanoparticles monitored by SERS. Talanta. 2015;138:183-9.

43. Wolny-Koladka KA, Malina D. Toxicity assessment of silver nanoparticles against Escherichia coli strains isolated from horse dung. IET Micro Nano Lett. 2017;12:772-6

44. Tartanson MA, Soussan L, Rivallin M, Pecastaings S, Chis CV, Penaranda D, et al. Dynamic mechanisms of the bactericidal action of an A12O3-TiO2-Ag granular material on an Escherichia coli strain. Appl Environ Microbiol. 2015;81:713542.

45. Singh P, Kim YJ, Singh H, Wang C, Hwang KH, Farh Mel-A, et al. Biosynthesis, characterization, and antimicrobial applications of silver nanoparticles. Int J Nanomed. 2015;10:2567-77.

46. Ortego L, Gonzalo-Asensio J, Laguna A, Villacampa MD, Gimeno MC. (Aminophosphane)gold(I) and silver(I) complexes as antibacterial agents. J Inorg Biochem. 2015;146:19-27.

47. Upadhyay J, Kumar A, Gogoi B, Buragohain AK. Antibacterial and hemolysis activity of polypyrrole nanotubes decorated with silver nanoparticles by an in-situ reduction process. Mater Sci Eng C Mater Biol Appl. 2015;54:8-13.
48. Jain N, Bhargava A, Rathi M, Dilip RV, Panwar J. Removal of protein capping enhances the antibacterial efficiency of biosynthesized silver nanoparticles. PLoS One. 2015;10:e0134337.

49. Vardanyan Z, Gevorkyan V, Ananyan M, Vardapetyan H, Trchounian A. Effects of various heavy metal nanoparticles on Enterococcus hirae and Escherichia coli growth and protoncoupled membrane transport. J Nanobiotechnol. 2015;13:69.

50. Hajipour MJ, Fromm KM, Ashkarran AA, Jimenez de Aberasturi D, de Larramendi IR, Rojo T, et al. Antibacterial properties of nanoparticles. Trends Biotechnol. 2012;30:499-511.

51. Seil JT, Webster TJ. Antimicrobial applications of nanotechnology: methods and literature. Int J Nanomed. 2012;7:2767-81.

52. Pal S, Tak YK, Song JM. Does the antibacterial activity of silver nanoparticles depend on the shape of the nanoparticle? A study of the gram-negative bacterium Escherichia coli. Appl Environ Microbiol. 2007;73:1712-20.

53. Rai MK, Deshmukh SD, Ingle AP, Gade AK. Silver nanoparticles: the powerful nanoweapon against multidrugresistant bacteria. J Appl Microbiol. 2012;112:841-52.

54. Malina D, Sobczak-Kupiec A, Wzorek Z, Kowalski Z. Silver nanoparticles synthesis with different concentrations of polyvinylpyrrolidone. Dig J Nanomater Biostruct. 2012;7:1527-34

55. Mijnendonckx K, Leys N, Mahillon J, Silver S, Van Houdt R. Antimicrobial silver: uses, toxicity and potential for resistance. Biometals. 2013;26:609-21.

56. Graves JL Jr, Tajkarimi M, Cunningham Q, Campbell A, Nonga $\mathrm{H}$, Harrison $\mathrm{SH}$, et al. Rapid evolution of silver nanoparticle resistance in Escherichia coli. Front Genet. 2015;6:42. 